\title{
CARACTERIZAÇÃO FÍSICA E QUÍMICA DE FRUTOS DE ARAÇÁ-BOI (Eugenia stipitata McVAugh) EM LAVRAS - MG
}

Verônica Andrade dos Santos ${ }^{1}$, José Darlan Ramos ${ }^{2}$, Nathalia Vállery Tostes ${ }^{3}$, Fábio Oseis Reis Silva ${ }^{4}$, Leticia Gabriela Ferreira de Almeida ${ }^{5}$

${ }^{1}$ Eng. Agrônoma/ Pós doutoranda da Universidade Federal de Lavras-MG-Brasil. Email: veronicaandrad@yahoo.com.br

${ }^{2}$ Eng. Agrônomo/Prof. da Universidade Federal de Lavras-MG-Brasil.

${ }^{3}$ Graduanda Ciências Biológicas, Universidade Federal de Lavras -MG-Brasil.

${ }^{4}$ Eng. Agrônoma/ Pós doutorando da Universidade Federal de Lavra-MG-Brasil.

${ }^{5}$ Graduanda do curso de agronomia, Universidade Federal de Lavras-MG-Brasil.

Recebido em: 02/10/2017 - Aprovado em: 21/11/2017 - Publicado em: 05/12/2017 DOI: 10.18677/EnciBio 2017B15

\section{RESUMO}

O Araçá-boi é uma fruta de origem amazônica pouco conhecida no Brasil, possui elevado potencial para exploração comercial e utilização na agroindústria. $O$ presente trabalho objetivou avaliar a qualidade física e química de frutos do Araçáboi em Lavras- MG para determinar seu potencial na região. Os frutos foram colhidos em propriedade particular na zona rural de Lavras-MG, no período de janeiro a março de 2017, quando apresentavam a casca com a coloração totalmente amarelada, em plena maturação. $O$ delineamento estatístico utilizado foi inteiramente casualizado, em esquema fatorial $3 \times 3$, sendo o primeiro fator três plantas de Araçazeiro-boi e o segundo fator três períodos de avaliação de frutos (janeiro, fevereiro e março). A cada trinta dias por um período de três meses foram realizadas as coletas dos frutos e avaliados as características de massa total dos frutos (MT, g), diâmetros longitudinal (DL em $\mathrm{mm}$ ) e transversal (DT em mm), relação (DT/DL), número de sementes, massa total da semente (MTS em g), pH, sólidos solúveis totais (Brix), e acidez total titulável (ATT, \% ácido cítrico). O Araçá-boi demonstrou ser uma espécie apta para o plantio na região de Lavras MG. Dentre as três plantas avaliadas a planta 1 se destacou nas características de massa de frutos, número de sementes, $\mathrm{pH}$, sólidos solúveis totais e acidez total titulável em relação às demais plantas.

PALAVRAS-CHAVE: Araçazeiro, frutas da Amazônia, qualidade de frutos.

\section{PHYSICAL AND CHEMICAL CHARACTERIZATION OF ARAÇÁ-BOI FRUITS (Eugenia stipitata McVAugh) IN LAVRAS - MG}

\begin{abstract}
Araçá-boi is a fruit of Amazonian origin little known in Brazil, it has high potential for commercial exploitation and use in agroindustry. The present work aimed to
\end{abstract}


evaluate the physical and chemical quality of Araçá-boi fruits in Lavras-MG, to determine their potential in the region. The fruits were harvested in private property in the rural area of Lavras-MG, from January to March, 2017, when they presented the bark with totally yellowish coloration, in full ripeness. The statistical design used was completely randomized, in a factorial scheme $3 \times 3$, the first factor being three Araçazeiro-boi plants and the second factor three periods of fruit evaluation (January, February and March). The fruits were collected every thirty days for a period of three months and the characteristics of: total fruit mass (MT, g), longitudinal (DL in $\mathrm{cm}$ ) and transverse (DT in $\mathrm{cm}$ ) diameters, / Total number of seeds, total seed mass (MTS in $\mathrm{g}$ ), $\mathrm{pH}$, total soluble solids (Bix), and total titratable acidity (ATT, \% citric acid). The Araçá-boi proved to be a suitable species for planting in the region of Lavras MG. Among the three evaluated plants, plant 1 was distinguished in fruit mass characteristics, seed number, $\mathrm{pH}$, total soluble solids and total titratable acidity in relation to the other plants.

KEYWORDS: Araçazeiro, fruits of the Amazon, fruit quality.

\section{INTRODUÇÃO}

O Brasil é um país de notável biodiversidade onde se encontram diversas frutas de grande potencial econômico, sabores diferenciados e marcantes. O país possui uma série de plantas com características endêmicas, e diversas espécies nativas que ganharam destaque na economia mundial, no entanto, a maior parte das atividades do agronegócio nacional está relacionada com espécies exóticas introduzidas no país. Este fator demonstra que o Brasil possui um grande potencial ainda não explorado, e grandes oportunidades para serem aproveitadas (BRASIL, 2017).

O Araçá-boi (Eugenia stipitata Mcvaugh) é uma espécie da Amazônia ocidental, um arbusto de aproximadamente três metros de altura, que possui produção durante o ano todo, seus frutos são bagas globosas de coloração amarelada, com elevado volume de polpa, sua importância econômica está relacionada ao alto teor de vitamina $\mathrm{C}$, proteínas, carboidratos, fibras e sais minerais (GENTIL; CLEMENT, 1996).

Apesar do sabor da fruta não ser agradável ao paladar dos consumidores devido à alta acidez, seus frutos vem ganhando destaque no setor agroindustrial, possui constância de produção durante o ano, propriedades nutracêuticas, elevado volume de polpa, e a acidez marcante faz com que os frutos sejam ideais para a indústria de sucos, geleias, sorvetes e néctares (ROGEZ et al., 2004).

Umas das opções de destino do Araça-boi é a fabricação de polpa em escala industrial, a transformação das frutas em polpa se apresenta como solução prática, pois viabiliza sua utilização como matéria-prima no desenvolvimento de novos produtos, favorecendo as operações de transporte e conservação, além disso, a polpa pode ser submetida à operação de concentração para reduzir os gastos com transporte a locais distantes e ser utilizada na elaboração de novos produtos, (TEIXEIRA et al., 2013).

Esta fruta vem sendo avaliada quanto ao seu teor de nutrientes e aproveitamento em produtos alimentícios, como sucos, geleias e doces. O Araçá boi é uma fruta rica em fibras e em vitamina A, B e C (NERI-NUMA et al., 2013). O araçá apresenta interessante potencial nutricional e funcional, demostrando boa atividade antioxidante e alto de fenólicos, além de altas taxas de proteína e carboidratos. Os frutos têm o seu sabor similar à goiaba, embora seja um pouco 
mais ácido e de perfume mais acentuado podem ser consumidos como ingrediente na produção de doces, sorvetes e bebidas (FRANZON et al., 2009).

No entanto a qualidade e aceitabilidade dos frutos estão diretamente relacionadas com seus aspectos físicos e químicos, que refletirão na aparência e no sabor. $\mathrm{O}$ conhecimento da associação entre os caracteres permite caracterizar frutos adequados para o consumo, também subsidiando o desenvolvimento de variedade para a produção que reúnam uma série qualidades (CRUZ et al., 2014).

É importante realizar estudos para compreender o comportamento e aptidão de novas de cultivares fora de sua região natural. Assim, o objetivo do trabalho foi à caracterização física e química de frutos do Araça-boi em Lavras-MG visando seu potencial produtivo para a região.

\section{MATERIAL E MÉTODOS}

O experimento foi conduzido no período de janeiro a março de 2017. Os frutos utilizados foram retirados de plantas de Araçá-boi localizadas em uma propriedade particular da zona rural de Lavras-MG. O município de Lavras está situado a 2114'06“ de latitude Sul e 4500'00" de longitude Oeste e altitude média de 919 metros. O clima da região é do tipo Cwb, temperado chuvoso (mesotérmico) (KÖPPEN; GEIGER,1928).

O delineamento estatístico utilizado foi inteiramente casualizado, em esquema fatorial $3 \times 3$ sendo o primeiro fator três plantas de Araçá-boi e segundo fator três períodos de avaliação de frutos (janeiro, fevereiro e março). Os frutos foram colhidos quando apresentavam a casca com a coloração totalmente amarelada, em plena maturação. De cada planta foram coletados 20 frutos em três repetições. Após a coleta os frutos foram transportados para o laboratório de pós colheita do setor de Olericultura do Departamento de Agricultura da Universidade Federal de Lavras/UFLA para avaliações físico-químicas. Os dados climatológicos durante o experimento se encontram na (Figura1).

A cada trinta dias por um período de três meses foram realizadas coletas de frutos em plena maturação e avaliados as características de: massa total dos frutos (MT em g), diâmetros longitudinal (DL em $\mathrm{mm}$ ) e transversal (DT em mm), relação DL/DT, número de sementes, massa total da semente (MTS, g), $\mathrm{pH}$, sólidos solúveis totais (SST, ${ }^{\circ}$ Brix), e acidez total titulável (ATT, \% ácido cítrico).

Os diâmetros longitudinal e transversal do fruto foram medidos com auxílio de paquímetro digital e expressos em $(\mathrm{mm})$ com os resultados foi realizada a relação DL/DT. O pH foi obtido através do Peagâmetro digital (AOAC, 2007), a amostra foi triturada e homogeneizada na proporção de 1:4 (10 g de polpa e 40 $\mathrm{mL}$ de água destilada) em politron e o filtrado utilizado para a análise. Os sólidos solúveis totais foram obtidos com uso de refratômetro digital, sendo os resultados expressos em ํㅜㄹix de sólidos solúveis totais (AOAC, 2007).

A determinação da acidez total titulável foi realizada por titulação com $\mathrm{NaOH} 0,1 \mathrm{~N}$, utilizando como indicador a fenolftaleína $1 \%$, foram utilizadas $10 \mathrm{ml}$ do homogenato filtrado para a titulação, após a trituração da polpa do fruto em politron na proporção de 1:5 (10 g de polpa e $50 \mathrm{~mL}$ de água destilada). 


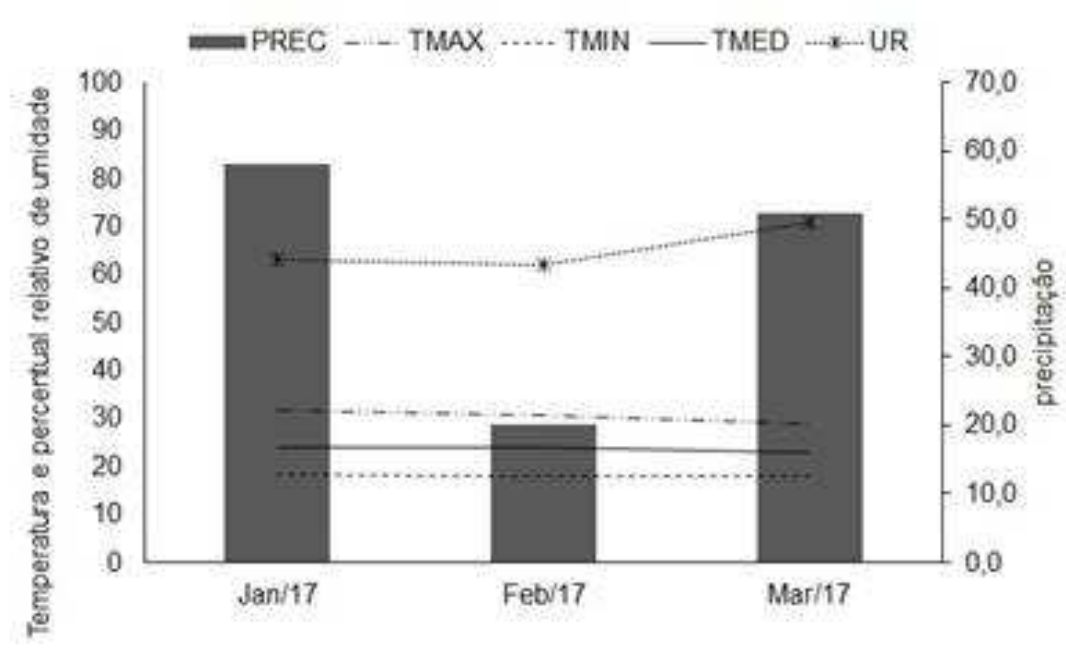

FIGURA 1- Precipitação acumulada (mm), temperaturas máximas, mínima e média para os meses de janeiro a março de 2017 em Lavras, MG.

Os dados foram submetidos à análise de variância de acordo, com o auxílio do software de análise estatística Sisvar® (FERREIRA, 2014). Os efeitos dos tratamentos quando necessário foram avaliados por meio do teste de Tukey, ao nível de $5 \%$ de significância.

\section{RESULTADOS E DISCUSSÃO}

De acordo com a (Figura 2), a massa dos frutos apresentou ampla variação de acordo com a planta estudada e com os meses de avaliação mostrando que essa variável é influenciada tanto por fatores genéticos, quanto ambientais. Pôdese verificar resultados superiores da planta 1 em relação as demais alcançando massa média de frutos de 188,26 e 257,55 g em janeiro e março respectivamente, fato que pode está relacionado com os dados climatológicos do período (Figura 1). Já os frutos da planta 2 e 3 apresentaram menor quantidade de massa, com média de todos os frutos de 106,34 g. Carvalho e Müller (2005) analisando frutos de araçá-boi de plantas matrizes encontraram valores médios de massa de $167 \mathrm{~g}$ por fruto, valor inferior aos encontrados na planta 1 do presente trabalho. 


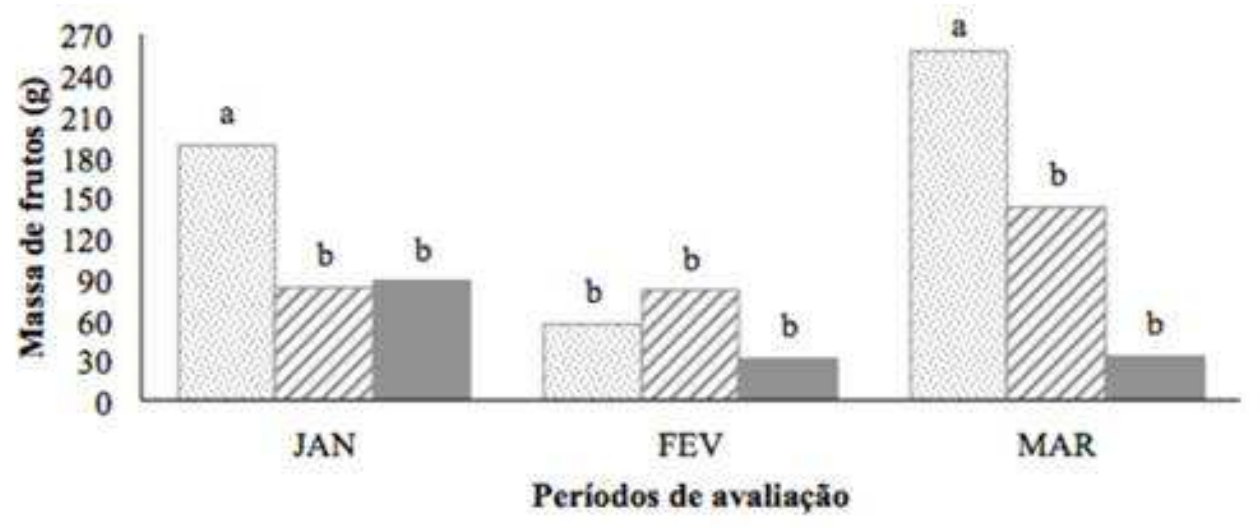

[PLANTA 1 ॠLANTA 2 "PLANTA 3

FIGURA 2 - Massa de frutos de Araçá-boi provenientes de plantas localizadas em Lavras-MG.

Uma das características mais importante para o araçá-boi é a massa do fruto, que depois de retirada as sementes, o restante é a polpa e a casca pouco espessa que envolve o fruto, e que também pode ser utilizada no processamento junto à polpa.

Para a característica do diâmetro transversal, houve diferença significativa em relação aos meses avaliados (Figura 3). A planta 1 alcançou o maior diâmetro transversal para os frutos colhidos em janeiro e março com média de $86,34 \mathrm{~mm}$, meses em que houve maior quantidade de chuvas e temperaturas semelhantes (Figura 1). Carvalho e Müller (2005) e Ferreira (1992) encontraram em frutos de araçá-boi para este parâmetro as médias de $78 \mathrm{~mm}$ e $72,5 \mathrm{~mm}$ respectivamente. Falcão et al., (2000) citam que nos meses com maior precipitação, os frutos de Araçá-boi apresentam maiores diâmetros, possivelmente nesse período houve maior absorção de água, no entanto características de frutos com diâmetros maiores pode está relacionado também a fatores relacionados a própria planta, além das condições de cultivo.

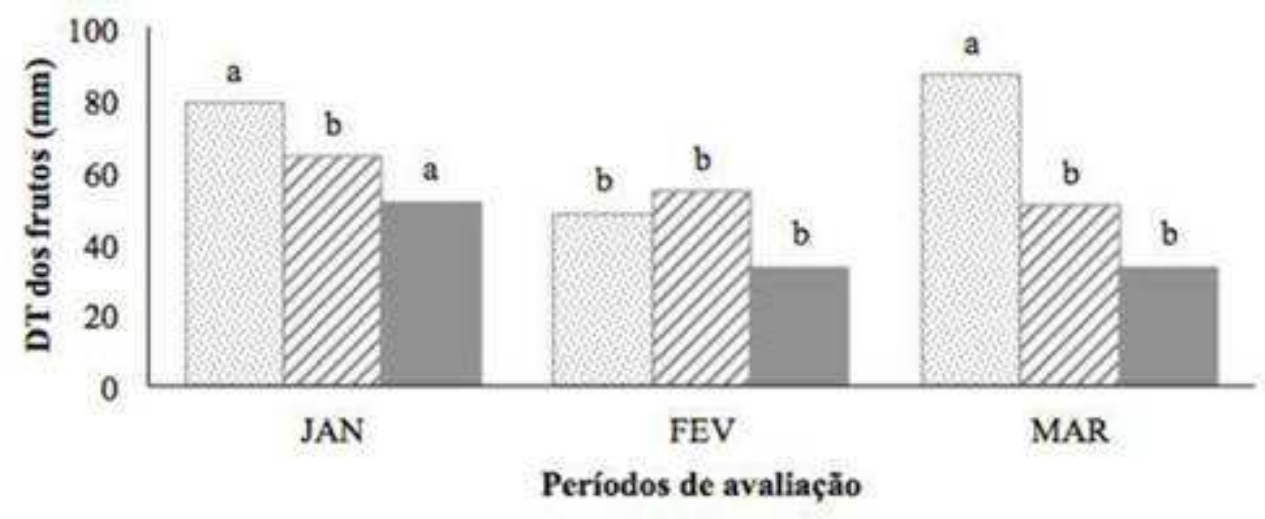

5PLANTA 1 PLANTA2 2 PLANTA 3

FIGURA 3 - Diâmetro transversal de frutos de Araçá-boi provenientes de plantas localizadas em Lavras-MG. 
Em relação ao diâmetro longitudinal dos frutos (Figura 4), houve diferença estatística entre as plantas, sendo que as plantas 1 e 2 apresentaram os maiores valores independente do período de avaliação. A média geral para todos os frutos analisados foi de $56,65 \mathrm{~mm}$ de diâmetro longitudinal, resultados próximos aos encontrados por (CARVALHO; MÜLLER, 2005) trabalhando com a mesma cultura.

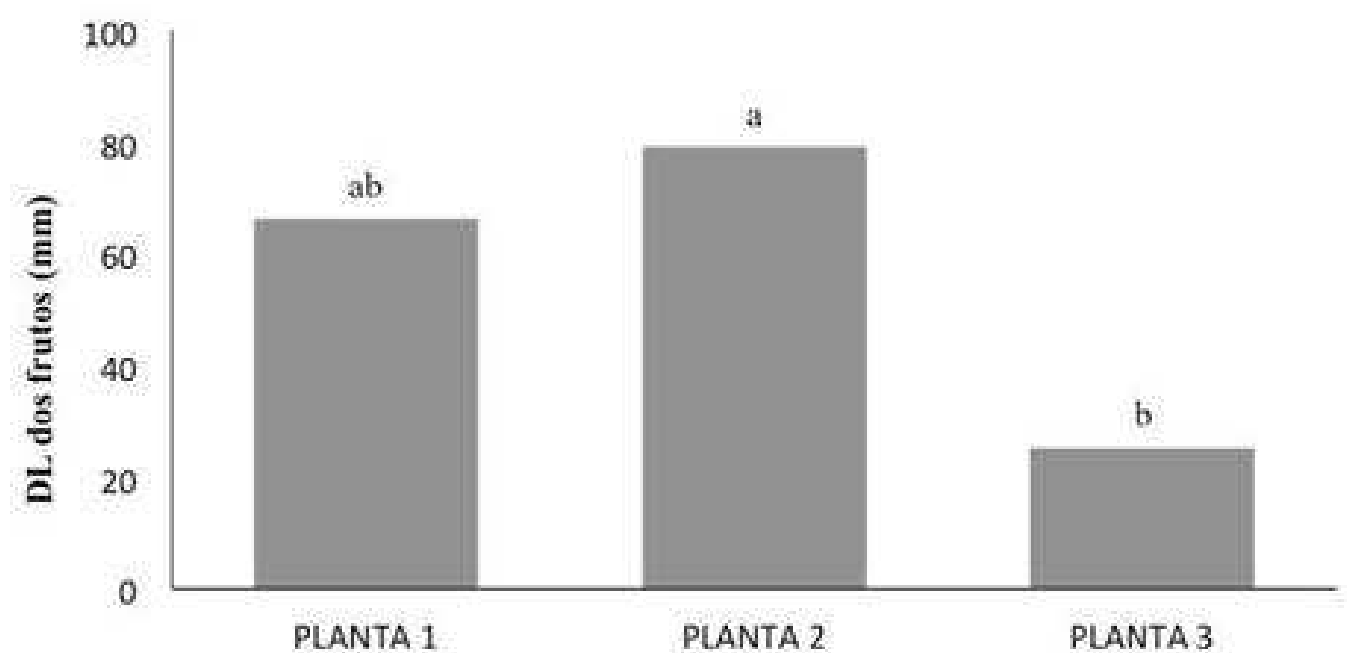

FIGURA 4 - Diâmetro longitudinal de frutos de Araçá-boi provenientes de plantas localizadas em Lavras-MG.

O formato do fruto pode ser verificado pela relação DT/DL (Figura 5). De acordo com Fortaleza et al., (2005), o índice de formato é um parâmetro físico importante para frutos destinados ao mercado in natura. Valores próximos de 1,0 indicam que os frutos possuem formatos mais arredondados e acima formato oblongo.

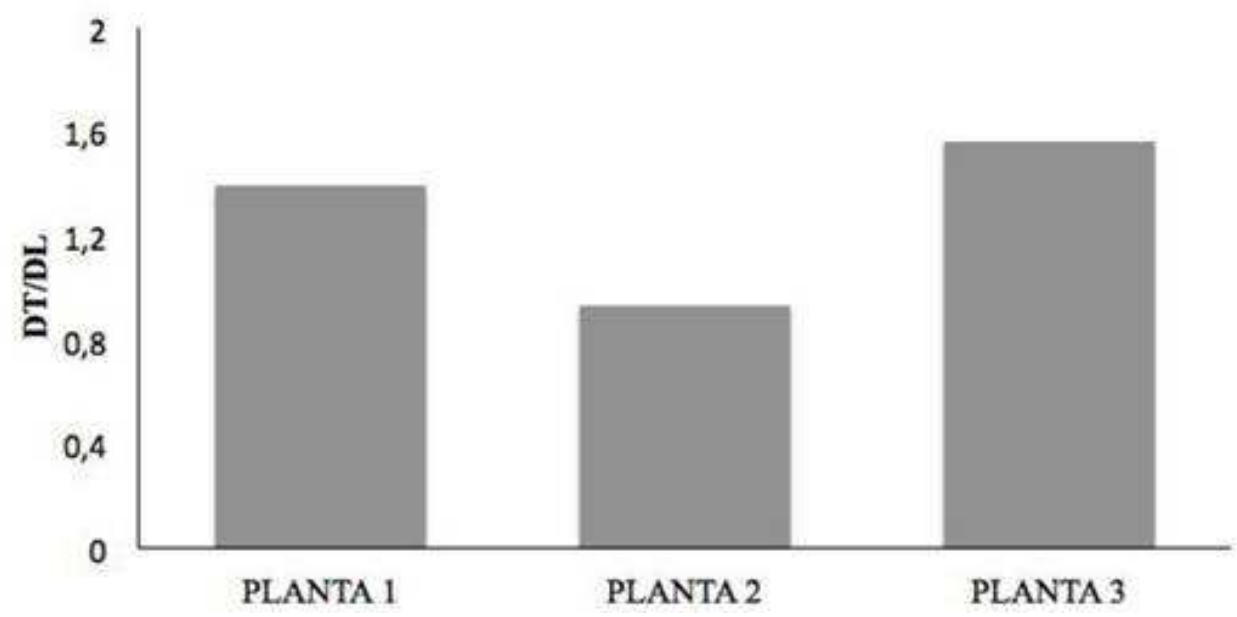

FIGURA 5 - Relação diâmetro longitudinal e transversal de frutos de Araçá-boi provenientes de plantas localizadas em LavrasMG. 
Pode-se observar na (Figura 5) que as plantas 1 e 3 produziram frutos de formato oblongo, enquanto os frutos da planta número 2 tiveram aspecto mais arredondado. Conforme o mesmo autor, frutos arredondados apresentam até $10 \%$ menos polpa que frutos oblongos. Ferro et al., (2016) também utilizaram o mesmo critério para estabelecer o formato de frutos de Mangaba.

Os frutos de Araçá-boi apresentaram em média de 2 a 8 sementes (Figura 6). A planta 1 alcançou o maior número de sementes, diferindo estatisticamente dos frutos das demais plantas nos meses de janeiro e de março, estes valores estão relacionados com a maior massa dos frutos também alcançada nestes meses pela planta 1 (Figura 2). O número médio máximo de sementes encontrado no presente trabalho se refere à planta 1 no mês de março que foi de 7,78 sementes por fruto, valor acima da média de todos os frutos coletados que foi de 4,64. Estes valores estão abaixo dos encontrados por Ferreira (1992), o qual relata médias de 12 sementes por fruto, e (CARVALHO ; MÜLLER, 2005) que encontraram média de 9,1 sementes, ambos para frutos de araçá-boi. Os resultados divergentes podem estar associados às condições de cultivo, assim como condições que a região Sudeste possui, totalmente distinta da região de origem do Araçá-boi.

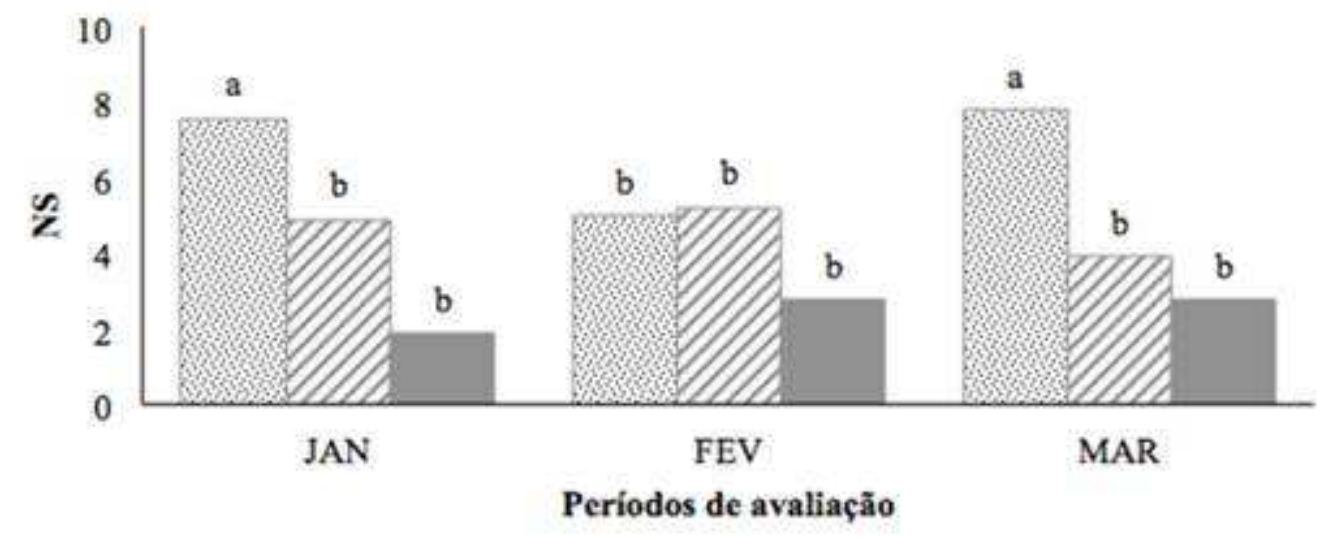

छ PLANTA 1 DLANTA2 2 PLANTA 3

FIGURA 6 - Número de sementes de frutos de Araçá-boi provenientes de plantas localizadas em Lavras-MG

Para o processamento da polpa pela indústria e não obstante para o consumo in natura, o elevado número de sementes no fruto não é uma boa característica, visto que, o interesse é ter frutos com poucas sementes e maior quantidade de polpa. Por outro lado, Sampaio et al., (2016) afirmam que semente em condições favoráveis dará origem à outra planta. Para a propagação, a semente é de grande importância, pois, atualmente é à base para formação de mudas desta espécie. Desta forma o maior número de sementes por frutos é uma característica importante para a propagação, fazendo com que a planta 1 tenha se destacado como possível progenitora. 
Em relação à massa das sementes, a planta 1 apresentou valores superiores às demais, com média 28,70 g (Figura 7). Resultados semelhantes foram observados por Ferreira (1992), trabalhando com a mesma espécie, encontrou valores de $33,58 \mathrm{~g}$. Em se tratando de propagação do Araçá-boi, sementes com maior quantidade de massa são importantes. Em geral, as sementes de maior tamanho são bem nutridas durante o seu desenvolvimento, possuindo embriões bem formados e com maior quantidade de substâncias de reserva, sendo, consequentemente, as mais vigorosas (CARVALHO; NAKAGAWA, 2000).

A maior quantidade de reserva aumenta a probabilidade de sucesso no estabelecimento da plântula, pois, permite a sobrevivência por maior tempo em condições ambientais desfavoráveis.

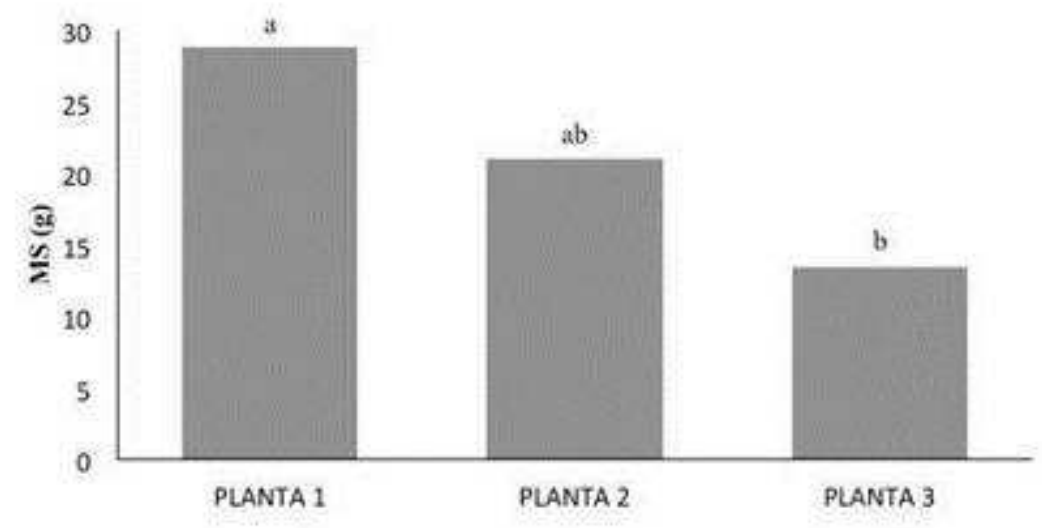

FIGURA 7 - Massa de sementes de frutos de Araçá-boi provenientes de plantas localizadas em Lavras-MG

As sementes quando alcançam o ponto de maturidade fisiológica estão com máximo de vigor e viabilidade, o que pode ser indicado pelo acúmulo máximo de matéria seca e de parâmetros adicionais, tais como peso, tamanho e teor de umidade, o processo geralmente é acompanhado por visíveis mudanças no aspecto externo e na coloração dos frutos e das sementes.

Há estudos que comprovam que sementes maiores e mais pesadas afetam significativamente o processo germinativo, onde são verificadas que sementes pequenas e mais leves germinam em menor quantidade, sendo por isso recomendado que sejam utilizadas as sementes maiores e com maior massa. Silva et al. (2016) detectaram diferenças significativas entre os tamanhos das sementes de moringa, as sementes grandes e consequentemente mais pesadas, proporcionaram maior porcentagem de emergência de plântulas e Silva et al., (2015) estudaram a classificação de sementes em espécie popularmente conhecida por quixabeira ou sapotiaba, a frutífera não cultivada frequente em seu habitat natural, verificaram influencia das sementes maiores na propagação. Para Barroso et al., (2016) os estudos biométricos de sementes auxiliam na obtenção de espécies superiores.

Em plantas de cacaueiro, Cilas et al., (2010), verificaram que a domesticação favorece sementes de tamanho maiores, como observado em 
genótipos derivados de cruzamentos entre cacaueiros cultivados, sendo esperado que o tamanho da semente tenha relação positiva com o vigor da planta. Dessa forma, a planta 1 no presente trabalho, por apresentar características biométricas superiores tanto de sementes como de frutos, teria maiores chances de gerar plântulas maiores e com maior quantidade de massa seca. O tamanho, teor de água, massa seca da semente, capacidade germinativa e ainda a massa seca da parte aérea das plântulas, são parâmetros que melhor determinaram a maturação fisiológica das sementes, espécie que apresenta características semelhantes de alta recalcitrância, assim como o araçá-boi (MATA et al., 2013).

As plantas apresentaram semelhança para os valores de $\mathrm{pH}$ dos frutos, no entanto, o pH dos frutos da planta 1 em todo o período avaliado foi menor que as demais plantas (Tabela 1).

TABELA 1 - Valores de pH, sólidos solúveis totais e acidez total titulável em frutos de Araçá- boi provenientes de plantas localizadas em LavrasMG.

\begin{tabular}{|c|c|c|c|}
\hline & Planta1 & Planta2 & Planta3 \\
\hline $\begin{array}{l}\text { Período de } \\
\text { avaliaçãa }\end{array}$ & \multicolumn{2}{|c|}{$\mathrm{pH}^{1}$} & \\
\hline Jan & $2,92 \mathrm{a}$ & $3,40 \mathrm{~b}$ & $3,36 \mathrm{~b}$ \\
\hline $\mathrm{Fev}$ & $2,42 \mathrm{a}$ & $2,90 \mathrm{~b}$ & $2,86 \mathrm{~b}$ \\
\hline Mar & $2,82 \mathrm{a}$ & $3,30 \mathrm{~b}$ & $3,26 \mathrm{~b}$ \\
\hline \multicolumn{4}{|c|}{ SST $^{2}$} \\
\hline Jan & $5,70 \mathrm{a}$ & $5,20 \mathrm{~b}$ & $4,10 \mathrm{c}$ \\
\hline $\mathrm{Fev}$ & $5,10 \mathrm{a}$ & $4,80 \mathrm{ab}$ & $4,53 \mathrm{~b}$ \\
\hline Mar & $5,43 \mathrm{a}$ & $5,13 \mathrm{ab}$ & $4,83 \mathrm{~b}$ \\
\hline \multicolumn{4}{|c|}{$\mathrm{ATT}^{3}$} \\
\hline & $22,61 \mathrm{a}$ & $14,16 \mathrm{~b}$ & $12,36 \mathrm{~b}$ \\
\hline
\end{tabular}

Acidez ou pH dos frutos tem relação com a presença de substâncias ácidas presentes naturalmente nesses vegetais, como os ácidos málico, cítrico e tartárico, especialmente. Os valores médios de $\mathrm{pH}$ e acidez favorecem a conservação das bebidas, em alguns casos não há necessidade da adição de ácido cítrico para inibir a proliferação de leveduras, contribuindo para garantir a segurança alimentar, (MOURA et al., 2014).

De acordo com os resultados obtidos (Tabela 1) os frutos pertencentes a todas as plantas apresentaram nos meses avaliados acidez elevada, no entanto, a planta 1 estatisticamente obteve maior acidez em relação às demais. A menor média para o parâmetro $\mathrm{pH}$ foi encontrada no mês de janeiro para a planta 1, com o valor de 2,42, enquanto a média geral foi de 3,03. Canuto et al., (2010) trabalhando com frutos da mesma espécie proveniente da floresta Amazônica encontraram valores médios de pH igual a 4, e Garzón et al., (2012) com os frutos 
da mesma frutífera adquiridos em Bogotá encontraram valores médios para o $\mathrm{pH}$ de 2,6. O que significa que apesar das condições climáticas das regiões serem diferentes, nos meses de janeiro a março houve condições climáticas de chuvas e temperaturas para suprir as necessidades das plantas e com isso às características encontradas em Lavras-MG se assemelharam aos frutos de locais de origem.

Para a formação de um gel estável e uso nas indústrias de polpa, é necessário obter um $\mathrm{pH}$ ideal e, para que esse processo aconteça de forma eficaz, é necessário obter pH no intervalo de 3,2 a 3,5, considerando sempre o teor de sólidos solúveis totais (CUNHA et al., 2016). Assim, acidez extremamente baixa prejudica a aceitação dos frutos pelos consumidores brasileiros. Entretanto, a polpa de araçá-boi adicionada ao açúcar tem sido utilizada com sucesso na fabricação de sorvetes, e apresenta potencial para o uso em formulações de sucos, geleias e néctares, especialmente quando associada às frutas de baixa acidez, como manga, mamão e maçã (SACRAMENTO et al., 2008).

Desta forma, quanto maior o valor de sólidos solúveis totais, maior a eficiência da indústria na fabricação da concentrada polpa, o que reduz os custos de produção. Os sólidos solúveis totais, o rendimento de polpa, e a presença de frutos verdes ou deteriorados são as principais características avaliadas. No presente trabalho as plantas 1 e 2 obtiveram os maiores valores para sólidos solúveis totais, sendo a maior média encontrada de 5,70 Brix para a planta $1 \mathrm{em}$ janeiro (Tabela 1), sendo um resultado interessante que eleva o sabor adocicado, no entanto, apresentam teor de sólidos solúveis, inferior à maioria dos frutos tropicais. Para (SILVINO; SANTOS, 2017) o sabor dos frutos é dependente direto das quantidades de açúcares (sólidos solúveis totais Brix) e da acidez total titulável.

Canuto et al., (2010) encontraram valores médios de 4,5 Brix, em frutos de Araçá-boi. Estudos relacionados a características físicas e químicas também

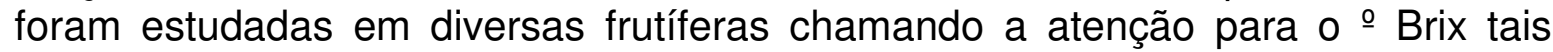
como no maracujazeiro por Santos et al., (2013), pupunha por Carvalho et al.,( 2013) e Ceriguela por Silva et al., (2016) . A acidez total titulável influencia o sabor do fruto porque mede a quantidade de ácidos cítricos. Em algumas frutíferas há uma acidez padrão aceita pelas indústrias, no entanto sabe-se que o teor elevado de ATT (acidez total titulável) diminui a necessidade de adição de acidificantes e propicia melhoria nutricional, segurança alimentar e qualidade sensorial (OLIVEIRA; SANTOS, 2015).

Baixos valores de acidez total titulável aliados a altos teores de sólidos solúveis totais são importantes para elevar a relação açúcares/acidez na determinação do ratio, o que torna o fruto mais adocicado, e assim, com maior aceitação no mercado in natura (MELETTI et al., 2005). De acordo com os valores encontrados de acidez total titulável (Tabela 1) nos frutos de araçá-boi na planta 1 foi de 22,61 sendo 8,45 a mais que a planta 2 e 10,25 em relação a planta 3 , sendo observada baixa relação de açúcar/acidez sendo constatado frutos altamente ácidos não aceito para o consumo ao natural, no entanto pode ser utilizado para uso na fabricação de sorvetes, cremes, tortas, bolos e sucos.

\section{CONCLUSÃO}

O Araçá-boi é uma espécie apta para o cultivo na região de Lavras - MG. A planta 1 se destacou nas características de massa de frutos, número de sementes, 
$\mathrm{pH}$, sólidos solúveis totais, acidez total titulável em relação às demais plantas.

Para um estudo mais detalhado do Araçá-boi na região se faz-se necessário a propagação vegetativa principalmente da planta 1 por apresentar características de frutos mais aceitáveis para indústria.

\section{REFERÊNCIAS}

AOAC - ASSOCIATION OF OFFICAL ANALITICAL CHEMISTS. Official methods of analysis of the Association of Official Analitical Chemists. 18th ed. Washington: AOC, p. 1750, 2007.

BARROSO, R. F., DE ASSIS SILVA, F., NOBREGA, J. S., DA SILVA, L. J., NOVAES, D. B.; FERREIRA, V. S. Biométria de frutos e sementes de Luetzelburgia auriculata (Allemão) Ducke. Revista Verde de Agroecologia e Desenvolvimento Sustentável, v. 11, n.5,156-160, $2016 . \quad$ Disponível em: http://dx.doi.org/10.18378/rvads.v11i5.4703 doi: 10.18378/rvads.v11i5.4703

CANUTO, G.A.B.; XAVIER, A.A.O.; NEVES L C.; BENASSI, M.T. Caracterização físico-química de polpas de frutos da Amazônia e sua correlação com a atividade anti-radical livre. Revista Brasileira de Fruticultura, Jaboticabal, v.32, n.4, p.11961205, 2010. Disponível em: <http://dx.doi.org/10.1590/S0100-29452010005000122>. doi: 10.1590/S0100-29452010005000122

CARVALHO, N.M.; NAKAGAWA, J. Sementes: ciência, tecnologia e produção. 4. ed. Jaboticabal: FUNEP, 588p, 2000.

CARVALHO, J.E.U. ; MÜLLER, C.H. Biometria e rendimento percentual de polpa de frutas nativas da Amazônia. Embrapa Amazônia Oriental-Comunicado Técnico, 139 (INFOTECA-E), 4p, 2005.

CARVALHO, A.V.; BECKMAN, J.C; MACIEL, R.A; FARIAS NETO, J.T Características físicas e químicas de frutos de pupunheira no estado do Pará. Revista Brasileira de Fruticultura, v. 35, n. 3, p. 763-768, 2013. Disponível em: http://dx.doi.org/10.1590/S0100-29452013000300013 doi:10.1590/S010029452013000300013

CILAS, C.; MACHADO, R.; MOTAMAYOR, J. C. Relations between several traits linked to sexual plant reproduction in Theobroma cacao L.: number of ovules per ovary, number of seeds per pod, and seed weight. Tree genetics \& genomes, v. 6, n.2, p. 219-216, 2010. Disponível em: <http://dx.doi.org/10.1007/s11295-009-02429>. doi: 10.1007/s11295-009-0242-9

COSTA JUNIOR, J.S.; ALMEIDA, A. A. C.; FERRAZ, A.B.F.; ROSSATTO, R.R.; SILVA, T.G.; SILVA, P.B.N.; MILITÃO, G.C.G.; CITO, A.M.G.L.; SANTANA, L.C.L.R.; CARVALHO, F.A. A.; FREITAS, R.M.; Citotoxic and leishmanicidal properties of garcinielliptone FC, a prenylated benzophenone from Platonia insignis. Natural Product Research v.27, n.4-5, p. 470-474, 2013. Disponível em: http://dx.doi.org/ 10.4172/2329-6836.1000e101 doi: 10.4172/2329-6836.1000e101 
CUNHA, M. F.; RIBEIRO, L. M. P.; DAMASCENO, K. A.; ALVESI, A. N.; GONÇALVES, R. M. S.; GONÇALVES, C. A. A. Acidez, sua relação com pH e qualidade de geleias e doces em barra. Boletim técnico IFTM, n. 2, p. 14-19, 2016.

CRUZ, C.D; CARNEIRO, P.C.S; REGAZZ,I A.J. Modelos biométricos aplicados ao melhoramento genético. v. 2, 3. ed. Viçosa-MG, Ed. UFV. 668p. 2014.

FALCÃO, M. A.; GALVÃO, R. M. S.; CLEMENT, C. R.; FERREIRA, S. A. N.; SAMPAIO S. G. Fenologia e Produtividade do Araçá-boi (Eugenia Stipitata, Myrtaceae) na Amazônia Central, Acta Amazônica, v. 30, n. 1, p. 9, 2000. Disponível em: https://dx.doi.org/10.1590/1809-43922000301021. doi: 10.1590/1809-43922000301021

FERREIRA, D. F. Sisvar: a Guide for its Bootstrap procedures in multiple comparisons. Ciência e agrotecnologia, Lavras, v. 38, n. 2, p. 109-112, 2014. Disponível em: <http://dx.doi.org/10.1007/s11295-009-0242-9>. doi: 10.1590/S141370542014000200001

FERREIRA, S. A. N. BIOMETRIA DE FRUTOS DE ARAÇÁ-BOI (Eugenia stipitata Mc Vaugh). Acta Amazônica, Manaus, v. 22, n. 3, p. 295-302, 1992. Disponível em: <http://dx.doi.org/10.1590/1809-43921992223302>. doi: 10.1590/180943921992223302

FERRO, J. H. D. A., LEMOS, E. E. P., FRÖELLICH, Â., SOUSA, J. D. S., \& FAUSTINO, G. D. L. Caracterização morfológica dos frutos de mangaba (hancornia speciosa gomes) produzidos em Alagoas. Revista Ciência Agrícola, v.13 n. v.1, p.61-67, 2016. Disponível em: http://www.seer.ufal.br/index.php/revistacienciaagricola/article/view/2054

FORTALEZA, J. M.; PEIXOTO, J. R.; JUNQUEIRA, N. T. V.; OLIVEIRA, A. T. D.; RANGEL, L. E. P. Características físicas e químicas em nove genótipos de maracujá-azedo cultivado sob três níveis de adubação potássica. Revista brasileira de fruticultura, Jaboticabal, v.27, n.1, p.124-127, 2005. Disponível em: <http://dx.doi.org/10.1590/S0100-29452005000100033>. doi: 10.1590/S010029452005000100033

FRANZON, R. C. et al. Araçás do gênero Psidium Principais espécies, ocorrência, descrição e usos. Embrapa Cerrados, Planaltina, v. 1, p. 11-41, 2009.

GARZÓN, G. A.; NARVÁEZ-CUENCA, C. E.; KOPEC, R. E.; BARRY, A. M.; RIEDL, K. M.; SCHWARTZ, S. J. Determination of carotenoids, total phenolic content, and antioxidant activity of Arazá (Eugenia Stipitata McVaugh), an Amazonian fruit. Journal of agricultural and food chemistry, v. 60, n.18, p. 4709-4717, 2012. Disponível em: <http://dx.doi.org/10.1021/jf205347f>. doi: 10.1021/jf205347f

GENTIL, D. F. O.; CLEMENT, C. R. The araza (Eugenia stipitata): results directions. Interamerican Society For Tropical Horticulture, Curitiba, p. 83-89, 1996. Disponível em: http://dx.doi.org /10.1533/9780857092762.98 doi: $10.1533 / 9780857092762.98$

KÖPPEN, W.; GEIGER, R. Klimate der Erde. Gotha: Verlag Justus Perthes. Wall- 
map $150 \mathrm{~cm}$ x 200cm, 1928.

MATA, M. F.; SILVA, K. B.; BRUNO, R. L. A.; FELIX, L. P.; FILHO, S. M.; ALVES, E. U. Maturação fisiológica de sementes de ingazeiro (Inga striata) Benth. Semina ciências Agrárias, v. 34, n. 2, p. 549-566, 2013. Disponível em: < http://dx.doi.org/10.5433/1679-0359.2013v34n2p549>. doi: 10.5433/16790359.2013v34n2p549

MELETTI, L. M. M.; SOARES-SCOTT, M. D.; BERNACCI, L. C.; PASSOS, I. D. S. "Melhoramento genético do maracujá: passado e futuro". Maracujá: germoplasma e melhoramento genético. Planaltina: Embrapa Cerrados, v. 1, p. 55-78, 2005.

BRASIL, Ministério do Meio Ambiente. Biodiversidade Brasileira. Disponível em: http://www.mma.gov.br/biodiversidade/biodiversidade-brasileira. Acesso em 26 jun. 2017.

MOURA, R. L.; FIGUEIRÊDO, R. M. F.; QUEIROZ, A. J. M. Processamento e caracterização físico-química de néctares goiaba-tomate. Revista Verde de Agroecologia e Desenvolvimento Sustentável, Pombal, v. 9, n. 3, p. 69-75, 2014. Disponível em: http://dx.doi.org/10.18378/rvads.v11i5.4703 doi: 10.18378/rvads.v11i5.4703

NERI-NUMA, I. A.; CARVALHO-SILVA, L. B.; MORALES, J. P.; MALTA, L. G.; MURAMOTO, M. T.; FERREIRA, J. E.; CARVALHO, J. E. de; RUIZ, A. L.; MARÓSTICA JUNIOR, M. R.; PASTORE, G. M. Evaluation of the antioxidant, antiproliferative and antimutagenic potential of araçá-boi fruit (Eugenia stipitata Mc Vaugh - Myrtaceae) of the Brazilian Amazon Forest. Food Research International, Barking, v. 50, n. 1, p. 70-76, 2013. https://doi.org/10.1016/j.foodres.2012.09.032

OLIVEIRA, E. N. A.; SANTOS, D. C. Tecnologia e processamento de frutos e hortaliças (organizadores), Natal: IFRN, p. 234, 2015.

ROGEZ, H.; BUXANT, R.; MIGNOLET, E.; SOUZA, J.N.S.; SILVA, E.M.; LARONDELLE, Y. Chemical composition of the pulp of three typical Amazonian fruits: araçá-boi (Eugenia stipitata), bacuri (Platonia insignis), and cupuaçu (Theobroma grandiflorum). European Food Research and Technology, Berlin, v.218, p.380-384, 2004.

SACRAMENTO, C. K.; BARRETTO, W. S.; FARIA, J. C. Araçá-boi: uma alternativa para agroindústria. Bahia Agrícola, Salvador, v.8, p.22-24, 2008.

SAMPAIO, M. F.; DO COUTO, S. R.; SILVA, C. A.; SILVA, A. C. A.; DA SILVA, A. A. S.; TEIXEIRA, A. L. Influência de diferentes substratos associados a métodos de superação de dormência na germinação e emergência de sementes de jatobá (Hymenaea Courbaril L.). Revista Farociência, v. 2, n. 1, p. 11-27, 2016. Disponível em: < http://www.faro.edu.br/farociencia/index.php/FAROCIENCIA/article/view/94>.

SANTOS, J. L. V. ; RESENDE, E. D. ; MARTINS, D. R.; GRAVINA, G. A.; CENCIA, S. A.; MALDONADO, J. F. M. Determinação do ponto de colheita de diferentes 
cultivares de maracujá. Revista Brasileira de Engenharia Agrícola e Ambiental. Campina Grande, v.17, n.7, p.750-755, 2013. Disponível em: www.scielo.br/pdf/rbeaa/v17n7/a09v17n7.pdf

SILVA, Q. J.; FIGUEIREDO, F. J.; LIMA, V. L. A. G.. Características físicas e químicas de Cirigueleiras cultivadas na Zona da Mata Norte de Pernambuco. Revista Ceres, v. 63, n. 3, p. 285-290, 2016. Disponível em: http://dx.doi.org/10.1590/0034-737X201663030002 doi: 10.1590/0034737X201663030002

SILVA, K. B.; BRUNO, R. L. A.; MELO, P. A. F. R. Qualidade fisiológica de sementes de Sideroxylon obtusifolium (Roem. \& Schult.) Penn. classificadas pelo tamanho. Revista Brasileira de Biociências, v. 13, n. 1, 2015. Disponível em: http://www.ufrgs.br/seerbio/ojs/index.php/rbb/article/view/2553

SILVINO, R., SILVA, G.; SANTOS, O. V. Qualidade nutricional e parâmetros morfológicos do fruto cajá (Spondias Mombin L.) Desafios , v.4, n.2, p. 03-1, 2017. Disponível em: https://doi.org/10.20873/uft.2359-3652.2017v4n2p3 doi: 10.20873/uft.2359-3652.2017v4n2p3

TEIXEIRA, T. R.; OLIVEIRA, A. N.; RAMOS, A. M.. Efeitos da temperatura e concentração nas propriedades físicas da polpa de araçá-boi. Boletim do Centro de Pesquisa de Processamento de Alimentos, v. 31, n. 2, 2013. Disponível em: http://dx.doi.org/10.5380/cep.v31i2.34957 doi: 10.5380/cep.v31i2.34957 